\title{
Polyurethane film dressings and ceramide 2-containing hydrocolloid dressing reduce the risk of pressure ulcer development in high-risk patients undergoing surgery: a matched case-control study
}

This article was published in the following Dove Press journal:

Chronic Wound Care Management and Research

13 February 2015

Number of times this article has been viewed

\author{
Masushi Kohta' \\ Kazumi Sakamoto ${ }^{2}$ \\ Tsunao Oh-i ${ }^{3}$ \\ 'Medical Engineering Laboratory, \\ ALCARE Co, Ltd, Sumida-ku, Tokyo, \\ ${ }^{2}$ Department of Nursing, ${ }^{3}$ Department \\ of Dermatology, Tokyo Medical \\ University lbaraki Medical Center, \\ Ami, Ibaraki, Japan
}

Background: Numerous clinical challenges regarding adhesive dressings have shown that using an adhesive dressing could minimize or prevent superficial skin loss in patients at risk of developing pressure ulcers. However, evidence that polyurethane film dressings and ceramide 2-containing hydrocolloid dressing can reduce the risk of pressure ulcer development in highrisk patients undergoing surgery is limited. Therefore, we assessed the effects of application of these dressings for reducing the risk of pressure ulcer development in these patients and identified other risk factors.

Methods: A matched case-control study was conducted involving 254 patients at high risk for pressure ulcer development at one acute care hospital in Japan. No patients in this study had a pressure ulcer at the start of the study. Thirty-one patients developed a pressure ulcer during surgery, and these patients were defined as cases. Controls were randomly matched for sex and age ( \pm 4 years), from which 62 patients were selected. Medical records were obtained for preoperative factors, including age, sex, body mass index, diabetes mellitus, albumin, total protein, C-reactive protein, white cell count, red cell count, and hemoglobin, and for intraoperative factors, including dressing application, operation time, body position, and surgery type. The odds ratio (OR) and 95\% confidence interval (CI) were determined to identify risk factors for pressure ulcer development in patients undergoing surgery.

Results: By multiple logistic regression analysis, there was a significantly reduced risk of pressure ulcer development for patients who had dressing applications as compared with those without dressing applications (OR 0.063; 95\% CI 0.012-0.343; $P=0.001$ ). Prone position (OR 8.791; 95\% CI 1.630-47.400; $P=0.01$ ), prolonged operation time (OR 1.684; 95\% CI 1.189-2.385, $P=0.003$ ), and reduced body mass index (OR $0.774 ; 95 \%$ CI $0.584-0.948 ; P=0.02$ ) were also significant predictive risk factors for development of a pressure ulcer.

Conclusion: Application of film dressing and ceramide 2-containing hydrocolloid dressing reduced the risk of pressure ulcer development in high-risk patients undergoing surgery.

Keywords: pressure ulcer prevention, operating room, wound dressing, friction

\section{Introduction}

Pressure ulcers remain a major health problem worldwide. The incidence rates for pressure ulcer development are in the range of $0 \%-6.6 \%$ in acute care settings. ${ }^{1-3}$ However, other studies showed that the risk of pressure ulcer development in patients undergoing surgery was higher, with incidence rates ranging from $6.8 \%$ to $42.0 \%{ }^{4-6}$ 
This increased incidence was due to numerous risk factors that only involved the intraoperative period. Pressure ulcer development had detrimental effects on these patients, including increased hospital stays and medical costs. ${ }^{7,8}$ Thus, nursing interventions for patients at high risk of pressure ulcer development in the operating room are key factors for successfully preventing pressure ulcers, for both patient safety and economic reasons.

Pressure ulcer development is defined as any area of the skin or underlying tissue that has been damaged due to unrelieved pressure or pressure in combination with extrinsic factors, including friction and shear. ${ }^{9}$ The risk for pressure ulcer development is higher in operating rooms than in the general acute care setting, because these patients are immobilized on an operating table for long periods or friction that is generated along with a shearing force on sites predisposed to development of a pressure ulcer development when changing patient posture. ${ }^{6,10}$ These extrinsic factors can occlude blood vessels and reduce blood flow, which results in skin damage..$^{11,12}$

Patient-associated factors during the preoperative period also contribute to the risk of a pressure ulcer development, and include patient age, a lower body mass index (BMI), diabetes mellitus, and lower albumin, hematocrit, and hemoglobin values. ${ }^{13-16}$ Previous assessments and programs suggested taking steps for preventing pressure ulcers by focusing on prevention rather than wound treatment. ${ }^{17,18}$ However, best practices for pressure ulcer development prevention in the operating room have not been established.

A promising approach to prevent pressure ulcer development in the operating room is to disperse excessive body pressure using a pressure redistribution support surface. Japanese consensus guidelines showed that using a support surface on the operating table reduced the incidence of pressure ulcer development. ${ }^{19}$ In our hospital, for standard prophylactic care, a viscoelastic polyurethane foam (Soft-nurse ${ }^{\circledR}$; LAC Healthcare Ltd, Osaka, Japan) is used for body pressure dispersion on the operating table for all patients at high risk of pressure ulcer development. Furthermore, our surgical team lifts and does not slide these patients to avoid friction and shearing forces when establishing a specific surgical position, such as prone, lateral, or lithotomy. However, there is no consensus regarding effective friction coefficient relief or shearing force reduction for patients at high risk of pressure ulcer development, who are undergoing surgery.

Numerous clinical studies have shown that using adhesive dressings could minimize or prevent superficial skin loss in patients at risk of developing a pressure ulcer development. ${ }^{20-26}$ This positive effect was typically found for film dressings and ceramide 2-containing hydrocolloid dressing used in elderly bedridden patients in Japanese hospitals. A polyurethane film dressing reportedly had a relatively low friction coefficient and resulted in reduced pressure ulcer development on the sacral area among bedridden patients in the general ward. ${ }^{23}$ Furthermore, the ceramide 2-containing hydrocolloid dressing, designed to reduce friction and shearing forces, facilitated recovery of the skin's barrier function and effectively prevented pressure ulcer development in general wards and intensive care units. ${ }^{21,26}$ However, there is limited evidence that these dressings can reduce the risk of pressure ulcer development in patients undergoing surgery. ${ }^{20}$ Thus, clinical nursing studies are required to verify the effects of application of dressing by comparing patients who develop a pressure ulcer development with those who do not when undergoing surgery.

Based on the findings noted above, we hypothesized that polyurethane film dressings and ceramide 2-containing hydrocolloid dressing applied to predisposed skin areas in patients at high risk of pressure ulcer development would reduce such a risk. In this study, we investigated our hypothesis by conducting a matched case-control study in one Japanese acute care hospital. The primary purpose of this study was to assess the effects of these dressing applications in patients at high risk of pressure ulcer development when undergoing surgery. Our secondary purpose was to identify other risk factors.

\section{Materials and methods Study design}

We conducted a matched case-control study that included patients admitted to Tokyo Medical University Ibaraki Medical Center, a 501-bed acute care hospital in Ibaraki, Japan. The overall prevalence of pressure ulcers in this hospital from April 2013 to March 2014 was determined to be $1.3 \%$. Our study was conducted in accordance with the regulations for clinical research established by this hospital. Written informed consent was obtained from all patients. All aspects of this research were in accordance with the principles set out in the Declaration of Helsinki. ${ }^{27}$

For purposes of pressure ulcer development prevention, we used two types of adhesive thin-layered dressing, polyurethane film dressing (Opsite ${ }^{\circledR}$; Smith and Nephew Wound Management KK, Tokyo, Japan; Tegaderm ${ }^{\circledR}$; 3 M Health Care Ltd, Tokyo, Japan) or Multifix ${ }^{\circledR}$ (Alcare Corporation, Tokyo, Japan) and a ceramide 2-containing hydrocolloid dressing (Remois Pad ${ }^{\circledR}$; Alcare Corporation). 


\section{Patients}

There were 254 patients at high risk of pressure ulcer development in the study hospital during the period from April 2013 to January 2014. In Japan, patients undergoing surgery and at high risk of pressure ulcer development are defined as follows: 1) patients placed in a specific position such as prone, lateral, or lithotomy and 2) patients for whom the operating time is over 6 hours under general anesthesia. In this study, the patients satisfied at least one of the definitions: only 1) (194 patients, 76\%), only 2) (40 patients, 16\%), and both 1) and 2) (20 patients, $8 \%$ ). Clinical management of these patients was conducted by hospital staff members who implemented effective pressure ulcer development prevention practices through an interdisciplinary with incentive care system. ${ }^{28}$ These practices had been shown to be beneficial with regard to accelerating wound healing and cost-effectiveness. ${ }^{28}$

In our hospital, film dressings or ceramide 2-containing hydrocolloid dressing were applied to the breast area and iliac crests in the prone position, sacral area and scapulae in the lithotomy position, and the axillae and iliac crests in the lateral position. Additionally, these dressings were applied to the sacral area and scapulae in the supine position when the operating time was over 6 hours under general anesthesia.

Some additional prevention strategies were employed for all patients at high risk of pressure ulcer development in our hospital. In the preoperative period, skin assessment in each patient was performed by a floor nurse to check any skin complications, eg, maceration, dry skin, or skin roughness. When these skin complications appeared, appropriate skin care was provided by a certified expert nurse (in wound, ostomy, and continence [WOC]) to prevent tissue damage during surgery. Each patient was laid on a pressure redistribution support surface, and the surgical team was required to lift and not slide the patient to minimize friction or shearing force. In the intraoperative period, water-absorbing pads were put between the body and the pressure redistribution support surface to protect the skin from antiseptic solution.

We were able to evaluate 238 of our 254 patients. We excluded 16 patients due to a lack of data on the presence or absence of a pressure ulcer development. Of these 238 patients, 31 developed a pressure ulcer development (defined as the cases). We randomly selected 62 sex-matched and agematched ( \pm 4 years) patients who did not develop a pressure ulcer development as controls, as in previous research. ${ }^{29}$ This gave a 1:2 match for cases to controls.

The sample size was based on a power of 0.08 and an alpha of 0.05 , assuming the rates of dressing application in patients with or without pressure ulcer development to be $20 \%$ or $55 \%$, respectively. Therefore, we needed 29 casecontrol sets in this study.

Study bias was minimized as follows: all case and control patients were selected from the same hospital and were at high-risk of pressure ulcer development, which reduced the bias of patient characteristics, and matching for sex and age reduced the potential effects of these two likely confounders.

\section{Data collection}

Sites predisposed to pressure ulcer development depend on the type of surgery and the patient's body type. Well-known predisposed sites are the breast, iliac crests, genitalia, and chin in the prone position, the shoulder and sacral area in the lithotomy position, and the axillae, iliac crests, and legs in the lateral position. ${ }^{17}$ The sites predisposed to development of a pressure ulcer development in each patient were determined by the WOC nurse along with floor nurses and surgical nurses during the preoperative periods. The WOC nurse determined which dressing was used before surgery without any strict criteria, but the ceramide 2-containing hydrocolloid dressing tended to be used for patients who perspired more heavily. The surgical nurse applied dressings to the skin in the operating room before general anesthesia. One day after surgery, the dressings were carefully removed by the floor nurse.

A pressure ulcer development was visually observed by one WOC nurse within 24 hours post-surgery, as in a previous report. ${ }^{20}$ When a pressure ulcer developed, its stage was judged by utilizing the Japanese standard DESIGN-R assessment tool, whereby: $\mathrm{d} 1$ represents nonblanchable erythema; $\mathrm{d} 2$ represents a lesion extending to the dermis; $\mathrm{d} 3$ represents a lesion extending into the subcutaneous tissue; $\mathrm{d} 4$ represents a lesion extending to muscle, tendon, and bone; $\mathrm{d} 5$ represents a lesion extending into an articular or body cavity; and DU indicates that measurement of depth is impossible. ${ }^{30,31}$

All data were obtained from medical records. The records of cases and control patients were also reviewed for the following medical details: preoperative data on age, sex, BMI, diabetes mellitus, albumin, total protein, C-reactive protein, white blood cell count, red blood cell count, and hemoglobin; and intraoperative data on dressing application, operation time, position type, and surgery type. The preoperative and intraoperative variables selected in this study are known to be risk factors for pressure ulcer development. ${ }^{13-18}$ Data collection and outcome assessment were not blinded in this study. 


\section{Data analysis}

Results for continuous variables were expressed as the mean \pm standard deviation and those for categorical variables were expressed as percentages. The nonparametric Mann-Whitney $U$ test was used to compare patient group results for continuous variables and the Chi-square test was used to compare results for categorical variables. A $P$-value of $<0.05$ was considered to be statistically significant and a $P$-value of $<0.1$ was considered to indicate a marginal trend toward significance. Missing values were excluded during our data analysis.

The odds ratios (ORs) for pressure ulcer development with dressing applications and for other relevant predictors were estimated by logistic regression analysis after first using a univariate model for each significant and marginal predictor derived from patient characteristics. Finally, logistic regression analysis was conducted using a multivariate model that included all variables that were either a significant or marginal predictor in a univariate model. A $P$-value of $<0.05$ derived from logistic regression analysis was used to identify significant predictors for pressure ulcer development. All statistical analyses were conducted using Statistical Package for the Social Sciences version 20.0 software (IBM Corporation, Tokyo, Japan).

\section{Results}

\section{Pressure ulcer development assessments}

During the study period, 31 patients developed a total of 40 pressure ulcers after undergoing surgery. Of these 40 pressure ulcers, $33(82.5 \%)$ were rated as $\mathrm{d} 1$, six $(15 \%)$ as $\mathrm{d} 2$, and one $(2.5 \%)$ as DU. The most common locations for a pressure ulcer development were the sacrum $(27.5 \%)$, breast $(20.0 \%)$, and iliac crest $(20.0 \%)$ (Table 1$)$.

Table I Pressure ulcer locations and stages

\begin{tabular}{llllllll}
\hline Location & PU numbers (\%) & d I & d2 & d3 & d4 & d5 & DU \\
\hline Chin & $3(7.5)$ & 3 & & & & & \\
Shoulder & $3(7.5)$ & 2 & I & & & & \\
Arm & I $(2.5)$ & I & & & & & \\
Axilla & I $(2.5)$ & I & & & & & \\
Breast & $8(20.0)$ & 7 & $\mathrm{I}$ & & & & \\
Iliac crest & $8(20.0)$ & 8 & & & & \\
Genitalia & I $(2.5)$ & 0 & $\mathrm{I}$ & & & \\
Sacrum & II $(27.5)$ & $\mathrm{I}$ & $\mathrm{I}$ & & & \\
Leg & $\mathrm{I}(2.5)$ & & $\mathrm{I}$ & & & \\
Not reported & $3(7.5)$ & $\mathrm{I}$ & $\mathrm{I}$ & & & \\
Total & $40(100)$ & 33 & 6 & & & $\mathrm{I}$ \\
\hline
\end{tabular}

Abbreviations: PU, pressure ulcer; $\mathrm{dl}$, nonblanchable erythema; $\mathrm{d} 2$, lesion extending to the dermis; $d 3$, lesion extending into subcutaneous tissue; $d 4$, lesion extending to muscle, tendon, and bone; $\mathrm{d} 5$, lesion extending into an articular or body cavity; DU, impossible to measure depth.

\section{Patient characteristics}

The demographic and clinical characteristics of patients with or without a pressure ulcer development are shown in Table 2. Age and sex were controlled for by matching. Thus, the mean age of pressure ulcer development cases was $69.4 \pm 11.1$ years and of controls was $69.2 \pm 10.4$ years, and was not significantly different $(P=0.93)$. There was also no difference with regard to sex $(P=1.00)$.

BMI values and serum albumin levels were lower for cases than for controls, although these differences were only marginally significant ( $P=0.08$ and $P=0.06$, respectively). red blood cell counts were significantly lower for cases than for controls $(P=0.01)$. Operation time was longer for cases than that for controls, although only marginally different $(P=0.09)$.

Approximately $48 \%$ of the patients who developed a pressure ulcer development underwent surgery in the prone position, whereas only $24 \%$ of those without a pressure ulcer development had surgery in this position; this difference was significant $(P=0.04)$. Among the cases, only $29 \%$ had a film dressing or a ceramide 2-containing hydrocolloid dressing applied, whereas $68 \%$ of the controls had one of these dressings; this difference was also significant $(P=0.001)$.

\section{Associations between pressure ulcers and patient characteristics}

Based on statistically significant differences by univariate analyses $(P<0.05)$, serum albumin, red cell count, operation time, and applying a dressing appeared to be risk factors for pressure ulcer development. Reduced BMI was a potentially predictive risk factor $(P<0.1)$. Table 3 shows ORs, associated $95 \%$ confidence intervals (CIs), and the significance levels for the variables included in this analysis.

\section{Multiple logistic regression analysis results}

A multiple logistic regression model was used to identify factors that could predict pressure ulcer development in patients undergoing surgery. As shown in Table 4, the OR for applying a dressing was 0.063 (95\% CI 0.012-0.343; $P=0.001)$. Other significant risk factors were prone position (OR 8.791; 95\% CI 1.630-47.400; $P=0.01$ ), prolonged operation time (OR $1.684 ; 95 \%$ CI 1.189-2.385; $P=0.003)$, and reduced BMI (OR 0.774; 95\% CI 0.584-0.948; $P=0.02$ ).

\section{Discussion}

To the best of our knowledge, this is the first report on the effects of using film dressings and ceramide 2-containing 
Table 2 Characteristics of patients with or without pressure ulcers

\begin{tabular}{|c|c|c|c|c|}
\hline Characteristic & $\begin{array}{l}P U(+) \\
(n=3 I)\end{array}$ & $\begin{array}{l}P U(-) \\
(n=62)\end{array}$ & $P$-value & $\begin{array}{l}\text { Missing values } \\
\text { PU(+)/PU(-) }\end{array}$ \\
\hline Age, mean \pm SD (years) & $69.4 \pm 11.1$ & $69.2 \pm 10.4$ & 0.93 & $0 / 0$ \\
\hline Sex, male (\%) & $39 \%$ & $39 \%$ & 1.00 & $0 / 0$ \\
\hline Body mass index, mean $\pm S D$ & $22.2 \pm 3.6$ & $23.3 \pm 5.0$ & $0.08^{b}$ & $0 / 0$ \\
\hline Diabetes mellitus (\%) & $39 \%$ & $37 \%$ & 0.88 & $5 / 0$ \\
\hline Albumin, mean $\pm S D(g / d L)$ & $3.9 \pm 0.9$ & $4.2 \pm 0.5$ & $0.06^{\mathrm{b}}$ & $\mathrm{I} / \mathrm{I}$ \\
\hline Total protein, mean $\pm \mathrm{SD}(\mathrm{g} / \mathrm{dL})$ & $6.9 \pm 0.7$ & $7.1 \pm 0.7$ & 0.22 & $4 / 3$ \\
\hline C-reactive protein, mean $\pm \mathrm{SD}(\mathrm{mg} / \mathrm{dL})$ & $2.9 \pm 6.4$ & $0.8 \pm 2.0$ & 0.24 & $6 / 13$ \\
\hline White blood cell, mean $\pm \mathrm{SD}\left(\times 10^{3} / \mu \mathrm{L}\right)$ & $7.6 \pm 5.4$ & $6.5 \pm 1.7$ & 0.91 & $1 / 0$ \\
\hline Red blood cell, mean \pm SD $\left(\times 10^{3} / \mu \mathrm{L}\right)$ & 4. $1 \pm 0.6$ & $4.4 \pm 0.6$ & $0.0 \mathrm{I}^{\mathrm{a}}$ & $1 / 0$ \\
\hline Hemoglobin, mean \pm SD $(g / d L)$ & $12.0 \pm 3.0$ & $13.1 \pm 1.9$ & 0.18 & $1 / 2$ \\
\hline Operation time, mean \pm SD (hours) & $5.88 \pm 2.79$ & $4.73 \pm 1.65$ & $0.09^{b}$ & $2 / 0$ \\
\hline Position & & & & $0 / 0$ \\
\hline Prone (\%) & $48 \%$ & $24 \%$ & $0.04^{a}$ & \\
\hline Lateral (\%) & $30 \%$ & $34 \%$ & 0.76 & \\
\hline Lithotomy (\%) & $13 \%$ & $29 \%$ & 0.16 & \\
\hline Others (\%) & $9 \%$ & $13 \%$ & 0.73 & \\
\hline Surgery & & & & $0 / 0$ \\
\hline Orthopedic (\%) & $35 \%$ & $37 \%$ & 0.88 & \\
\hline Gastrointestinal (\%) & $19 \%$ & $24 \%$ & 0.37 & \\
\hline Neurosurgery (\%) & $16 \%$ & $8 \%$ & 0.24 & \\
\hline Thoracic (\%) & $13 \%$ & $18 \%$ & 0.85 & \\
\hline Others (\%) & $17 \%$ & $13 \%$ & 0.67 & \\
\hline Dressing application (\%) & $29 \%$ & $67 \%$ & $0.00 I^{\mathrm{a}}$ & $0 / 0$ \\
\hline
\end{tabular}

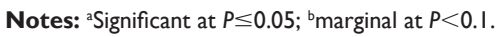

Abbreviations: $\mathrm{SD}$, standard deviation; $\mathrm{PU}(+)$, patients with pressure ulcer development; $\mathrm{PU}(-)$, patients without pressure ulcer development.

hydrocolloid dressing for patients at high risk of pressure ulcer development in the operating room at a Japanese acute care hospital. The most significant finding of this study was that applying these dressings for patients at high risk of pressure ulcer development was associated with a reduction in this risk when undergoing surgery (Table 4). This could be explained by the material properties of these dressings in terms of reducing the friction and shearing forces between a patient's body and the support surface.

Ohura et al support our explanation that shearing forces on both the superficial layers and subcutis layers were significantly reduced when conventional hydrocolloid dressings were applied to porcine skin..$^{32}$ Nakagami et al also reported that a hydrocolloid dressing with a low-friction external surface

Table 3 Univariate analysis results

\begin{tabular}{llll}
\hline & OR & $\mathbf{9 5 \% ~ C l ~}$ & P value \\
\hline Body mass index & 0.897 & $0.792-1.015$ & $0.09^{\mathrm{b}}$ \\
Albumin $(\mathrm{g} / \mathrm{dL})$ & 0.487 & $0.240-0.989$ & $0.04^{\mathrm{a}}$ \\
Red blood cell $\left(\times 10^{3} / \mu \mathrm{L}\right)$ & 0.426 & $0.204-0.889$ & $0.02^{\mathrm{a}}$ \\
Operation time (hours) & 1.279 & $1.035-1.582$ & $0.02^{\mathrm{a}}$ \\
Prone position & $2.81 \mathrm{I}$ & $1.030-7.676$ & $0.04^{\mathrm{a}}$ \\
Dressing application & 0.142 & $0.054-0.372$ & $0.00007^{\mathrm{a}}$ \\
\hline
\end{tabular}

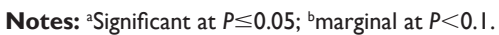

Abbreviations: $\mathrm{OR}$, odds ratio; $\mathrm{Cl}$, confidence interval. could significantly reduce shear forces on the heels of elderly people. ${ }^{22}$ Film dressing could have similar effects to reduce friction and shearing force.

Tissue damage may occur due to friction and shear when a patient is transferred to an operating table or placed in a particular surgical position. Furthermore, our in vitro preliminary study showed that a sustained shearing force was generated between a pressure redistribution support surface and a polymer-based skin model on an inclined table when applying pressure. This may result in tissue damage related to friction and shearing forces during surgery when using an inclined operating table. Thus, these dressings may reduce tissue damage due to a reduction in the friction coefficient

Table 4 Multiple logistic regression analysis results

\begin{tabular}{llll}
\hline & OR & $\mathbf{9 5 \% ~ C l ~}$ & $P$-value \\
\hline Body mass index & 0.774 & $0.584-0.948$ & $0.02^{\mathrm{a}}$ \\
Albumin $(\mathrm{g} / \mathrm{dL})$ & 0.276 & $0.065-1.167$ & 0.09 \\
Red blood cell $\left(\times 10^{3} / \mu \mathrm{L}\right)$ & 1.586 & $0.33 \mathrm{I}-7.597$ & 0.56 \\
Operation time (hours) & $\mathrm{I} .684$ & $1.189-2.385$ & $0.003^{\mathrm{a}}$ \\
Prone position & $8.79 \mathrm{I}$ & $1.630-47.400$ & $0.0 \mathrm{I}^{\mathrm{a}}$ \\
Dressing application & 0.063 & $0.012-0.343$ & $0.00 \mathrm{I}^{\mathrm{a}}$ \\
\hline
\end{tabular}

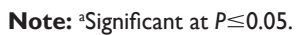

Abbreviations: $\mathrm{OR}$, odds ratio; $\mathrm{Cl}$, confidence interval. 
with an associated shearing force, and result in preventing pressure ulcer development.

Other characteristics, including prone position, prolonged operation time, and reduced BMI were significant independent predictors in our logistic regression analysis (Table 4). Sanada et al reported that patients with spinal cord injuries had a higher pressure ulcer development incidence rate in the prone position. ${ }^{33}$ These surgical patients were at risk of pressure ulcer development due to the surgical requirement to place them in a position with complete immobility and unrelieved pressure. In addition, surgical procedures in the prone position often use a Relton-Hall frame in Japan. The limited contact area between the body and operating table on the Relton-Hall frame results in high pressure placed on sites of bony prominences and with reduced blood flow. ${ }^{34}$ A prolonged operation time and reduced BMI were also predictive factors for pressure ulcer development, which is in agreement with previous reports. ${ }^{4,15}$

Thus, a body pressure dispersion mattress is required to reduce interface pressures. A previous report regarding a support surface, such as foam and gel pads, showed good results during the intraoperative period. ${ }^{35}$ In our hospital, there is general agreement that a support surface which disperses body pressure on an operating table should be used as standard care to prevent pressure ulcer development in patients undergoing surgery. However, it is difficult to completely prevent tissue damage in patients at high risk for ulcer development. Therefore, we recommended using an adhesive dressing to reduce the friction coefficient and shearing forces for pressure ulcer development prevention, particularly for patients at high risk for ulcer development who have longer operation times, lower BMI values, and surgery in the prone position.

Based on our results, applying dressings reduced the risk of pressure ulcer development in high-risk patients. However, our results could not be explained solely by the differences in quality of the dressing materials used. Future investigations should compare the results when using film dressings as compared with ceramide 2-containing hydrocolloid dressing.

There were several limitations in our study. First, only a small number of pressure ulcers developed during the limited study period. A high-level clinical study will be needed to achieve an adequate sample size to determine the effectiveness of applying dressings for pressure ulcer development prevention. Second, neither the cases nor control patients in this study were evaluated using a risk assessment tool during the preoperative period. For example, the Braden scale is a standard pressure ulcer development assessment tool for bedridden patients. ${ }^{19}$ However, the Braden scale for risk assessment is not adequate for patients who undergo surgery because these patients are immobile under general anesthesia, and thus would be exposed to moderate or severe conditions for pressure ulcer development. ${ }^{36}$ Although not helpful during the intraoperative period, this may be an effective tool during the preoperative period. ${ }^{4}$ Due to the retrospective nature of this study, we do not have any results for risk assessment scores, which may have been a confounder for all patients. In addition, we must note that the data for pressure ulcer development stages assessed by DESIGN-R has a limitation. The appearance of pressure ulcers during surgery cannot always show the depth of final tissue damage because DESIGN-R is primarily used for chronic stage of pressure ulcers. ${ }^{37}$ Finally, this study did not evaluate the effects of the possible risk factors on deep tissue injury because of the lack of long-term follow-up. Deep tissue injury is often formed in relatively obese patients undergoing longer periods of immobilization, and development of deep tissue injury requires at least several days.

\section{Conclusion}

Prevention is better than treatment for cases of pressure ulcer development. We conclude that applying film dressings and a ceramide 2-containing hydrocolloid dressing reduced the risk of pressure ulcer development in high-risk patients. The prone position, prolonged operation time, and reduced BMI were also risk factors associated with pressure ulcer development.

\section{Acknowledgments}

We would like to thank the nursing staff, including the head nurse, chief nurse, all members of the pressure ulcer development committee, and the surgery nurses of Tokyo Medical University Ibaraki Medical Center for their valuable cooperation. We would also like to thank Enago (http://www.enago. jp) for English language review.

\section{Author contributions}

All authors substantially participated in the conception, study design, data acquisition, and data analysis. All authors also contributed to drafting the manuscript or critical revisions for important intellectual content, and gave their final approval of the version published. Finally, all authors agree to be accountable for all aspects of this work to ensure that questions related to the accuracy or integrity of any part of this work are appropriately investigated and resolved. 


\section{Disclosure}

KS and TO were supported by funds from Alcare Corporation (Tokyo, Japan) regarding research on wound management. MK is an employee of Alcare Corporation. The authors have no other conflicts of interest to disclose related to this work.

\section{References}

1. Shahin ES, Dassen T, Halfens RJ. Incidence, prevention and treatment of pressure ulcers in intensive care patients: a longitudinal study. Int $J$ Nurs Stud. 2009;46(4):413-421.

2. Jenkins ML, O’Neal E. Pressure ulcer prevalence and incidence in acute care. Adv Skin Wound Care. 2010;23(12):556-559.

3. House S, Giles T, Whitcomb J. Benchmarking to the international pressure ulcer prevalence survey. J Wound Ostomy Continence Nurs. 2011;38(3):254-259.

4. Schultz A, Bien M, Dumond K, Brown K, Myers A. Etiology and incidence of pressure ulcers in surgical patients. AORN J. 1999;70(3): 434, 437-440, 443-449.

5. Kaizawa M, Momose M, Momose M, Sugiyama A, Ota K. [Intraoperative pressure ulcers in prone and lateral position: cause and prevention]. Jpn J PU. 2000;2(3):304-309. Japanese.

6. Ham W, Schoonhoven L, Schuurmans MJ, Leenen LP. Pressure ulcers from spinal immobilization in trauma patients: a systematic review. J Trauma Acute Care Surg. 2014;76(4):1131-1141.

7. Theisen S, Drabik A, Stock S. Pressure ulcers in older hospitalised patients and its impact on length of stay: a retrospective observational study. J Clin Nurs. 2012;21(3-4):380-387.

8. Padula WV, Mishra MK, Makic MB, Sullivan PW. Improving the quality of pressure ulcer care with prevention: a cost-effectiveness analysis. Med Care. 2011;49(4):385-392.

9. National Pressure Ulcer Advisory Panel, European Pressure Ulcer Advisory Panel. Pressure ulcer prevention recommendations. In Prevention and Treatment of Pressure Ulcers: Clinical Practice Guideline. Washington, DC, USA: National Pressure Ulcer Advisory Panel; 2009.

10. Lindholm C, Sterner E, Romanelli M, et al. Hip fracture and pressure ulcers - the Pan-European Pressure Ulcer Study - intrinsic and extrinsic risk factors. Int Wound J. 2008;5(2):315-328.

11. Bennett L, Kavner D, Lee BK, Trainor FA. Shear vs pressure as causative factors in skin blood flow occlusion. Arch Phys Med Rehabil. 1979;60(7):309-314.

12. Linder-Ganz E, Gefen A. The effects of pressure and shear on capillary closure in the microstructure of skeletal muscles. Ann Biomed Eng. 2007;35(12):2095-2107.

13. Okuwa M, Sanada H, Sugama J, et al. A prospective cohort study of lower-extremity pressure ulcer risk among bedfast older adults. Adv Skin Wound Care. 2006;19(7):391-397.

14. Lewicki LJ, Mion L, Splane KG, Samstag D, Secic M. Patient risk factors for pressure ulcers during cardiac surgery. AORNJ. 1997;65(5): 933-942.

15. Tschannen D, Bates O, Talsma A, Guo Y. Patient-specific and surgical characteristics in the development of pressure ulcers. Am J Crit Care. 2012;21(2):116-125.

16. Liu P, He W, Chen HL. Diabetes mellitus as a risk factor for surgeryrelated pressure ulcers: a meta-analysis. J Wound Ostomy Continence Nurs. 2012;39(5):495-499.

17. Walton-Geer PS. Prevention of pressure ulcers in the surgical patient. AORN J. 2009;89(3):538-551.

18. Price MC, Whitney JD, King CA, Doughty D. Development of a risk assessment tool for intraoperative pressure ulcers. J Wound Ostomy Continence Nurs. 2005;32(1):19-30.
19. The Japanese Society of Pressure Ulcers Revision Committee. [JSPU guidelines for the prevention and management of pressure ulcers (3rd ed)]. Jpn J PU. 2014;16(1):12-90. Japanese.

20. Imanishi K, Morita K, Matsuoka M, et al. Prevention of postoperative pressure ulcers by a polyurethane film patch. J Dermatol. 2006;33(3): 236-237.

21. Nakagami G, Sanada H, Konya C, Kitagawa A, Tadaka E, Tabata K. Comparison of two pressure ulcer preventive dressings for reducing shear force on the heel. J Wound Ostomy Continence Nurs. 2006;33(3): $267-272$.

22. Nakagami G, Sanada H, Konya C, Kitagawa A, Tadaka E, Matsuyama Y. Evaluation of a new pressure ulcer preventive dressing containing ceramide 2 with low frictional outer layer. J Adv Nurs. 2007;59(5): $520-529$.

23. Itou Y, Yasuda M, Yone J, Takatsugi K, Kubo T, Sato K. [Sacral polyurethane film dressing for prevention of pressure ulcers]. Jpn J PU. 2007;9(1):38-42. Japanese.

24. Brindle CT, Wegelin JA. Prophylactic dressing application to reduce pressure ulcer formation in cardiac surgery patients. J Wound Ostomy Continence Nurs. 2012;39(2):133-142.

25. Chaiken N. Reduction of sacral pressure ulcers in the intensive care unit using a silicone border foam dressing. JWound Ostomy Continence Nurs. 2012;39(2):143-145.

26. Park KH. The effect of a ceramide-containing dressing in preventing pressure ulcers. J Wound Care. 2014;23(7):347-353.

27. World Medical Association. World Medical Association Declaration of Helsinki: ethical principles for medical research involving human subjects. JAMA. 2013;310(20):2191-2194.

28. Sanada H, Nakagami G, Mizokami Y, et al. Evaluating the effect of the new incentive system for high-risk pressure ulcer patients on wound healing and cost-effectiveness: A cohort study. Int J Nurs Stud. 2009;47(3):279-286.

29. Kalava UR, Cha SS, Takahashi PY. Association between vitamin D and pressure ulcers in older ambulatory adults: results of a matched case-control study. Clin Interv Aging. 2011;6:213-219.

30. Matsui Y, Furue M, Sanada H, et al. Development of the DESIGN-R with an observational study: an absolute evaluation tool for monitoring pressure ulcer wound healing. Wound Repair Regen. 2011;19(3): 309-315.

31. Sanada H, Iizaka S, Matsui Y, et al. Clinical wound assessment using DESIGN-R total score can predict pressure ulcer healing: pooled analysis from two multicenter cohort studies. Wound Repair Regen. 2011;19(5):559-567.

32. Ohura T, Takahashi M, Ohura N Jr. Influence of external forces (pressure and shear force) on superficial layer and subcutis of porcine skin and effects of dressing materials: are dressing materials beneficial for reducing pressure and shear force in tissues? Wound Repair Regen. 2008;16(1):102-107.

33. Sanada H, Nagakawa T, Yamamoto M, Higashidani K, Tsuru H, Sugama J. The role of skin blood flow in pressure ulcer development during surgery. Adv Wound Care. 1997;10(6):29-34.

34. Kumagai A, Sugama J, Okuwa M, et al. [Relationship between interface pressure and development of pressure ulcer in prone position surgery using hall frame]. Jpn J PU. 2011;13(4):576-582. Japanese.

35. Aronovitch SA, Wilber M, Slezak S, Martin T, Utter D. A comparative study of an alternating air mattress for the prevention of pressure ulcers in surgical patients. Ostomy Wound Manage. 1999;45(3):34-40, 42-44.

36. Lewicki LJ, Mion LC, Secic M. Sensitivity and specificity of the Braden Scale in the cardiac surgical population. J Wound Ostomy Continence Nurs. 2000;27(1):36-41.

37. Kadono T. [Classification and surface evaluation of pressure ulcers]. In: Sanada H, Miyaji Y, editors. [New Visual Guide for Pressure Ulcers] Osaka, Japan: Nagai-Shoten, Osaka; 2012. Japanese. 
Chronic Wound Care Management and Research

Dovepress

\section{Publish your work in this journal}

Chronic Wound Care Management and Research is an international, peer reviewed, open access, online journal publishing original research, reviews, editorials, and commentaries on the causes and management of chronic wounds and the major issues related to chronic wound management. Topics also include chronic wounds as comorbidities to other

conditions, patient adherence to therapy, and the economic burden of chronic wounds. The manuscript management system is completely online and includes a very quick and fair peer review system, which is all easy to use. Visit http://www.dovepress.com/testimonials.php to read real quotes from published authors.

Submit your manuscript here: http://www.dovepress.com/chronic-wound-care-management-and-research-journal 